\title{
Huntington's Disease in Venezuela: 7 Years of Follow-up on Symptomatic and Asymptomatic Individuals
}

\author{
${ }^{1}$ John B. Penney, Jr., ${ }^{1}$ Anne B. Young, ${ }^{2}$ Ira Shoulson, ${ }^{3}$ Simon Starosta-Rubenstein, \\ ${ }^{4} \mathrm{~S}$. Robert Snodgrass, ${ }^{5} \mathrm{Juan}$ Sanchez-Ramos, ${ }^{6}$ Maria Ramos-Arroyo, ${ }^{7}$ Fidela Gomez, \\ ${ }^{8}$ Graciela Penchaszadeh, ${ }^{9} \mathrm{Jose}$ Alvir, ${ }^{10} \mathrm{Jesus}$ Esteves, ${ }^{10}$ Iris DeQuiroz, ${ }^{10}$ Nelson Marsol, \\ ${ }^{11}$ Humberto Moreno, ${ }^{12} \mathrm{P}$. Michael Conneally, ${ }^{10}$ Ernesto Bonilla, and ${ }^{8}$ Nancy S. Wexler
}

${ }^{I}$ Department of Neurology, University of Michigan, Ann Arbor, Michigan; ${ }^{2}$ Department of Neurology, University of Rochester, Rochester; ${ }^{8}$ Departments of Neurology and Psychiatry, Columbia University and the Hereditary Disease Foundation, New York; ${ }^{9}$ Long Island Jewish Medical Center, New Hyde Park, New York; ${ }^{4}$ Departments of Neurology and Pediatrics, University of Southern California, Los Angeles, California; ${ }^{5}$ Department of Neurology, University of Miami, Miami, ${ }^{7}$ Hialeah Hospital, Hialeah, Florida $;{ }^{12}$ Department of Medical Genetics, Indiana University Medical School, Indianapolis, Indiana, U.S.A.; ${ }^{3}$ Department of Neurology, Central University of Caracas, Caracas; Departments of ${ }^{10}$ Biochemistry and ${ }^{11}$ Genetics, University of Zulia, Maracaibo, Venezuela; ${ }^{6}$ Department of Genetics, Hospital Virgen del Camino, Pamplona, Spain.

\begin{abstract}
Summary: Persons symptomatic and at risk for Huntington's disease (HD) from a large extended family in the state of Zulia, Venezuela, have been followed prospectively for 7 years. Between 1981 and 1988, 593 people were examined, of whom 128 had symptomatic HD and 171 persons at risk had examination abnormalities that were insufficient to meet criteria for diagnosis. The remaining 294 had normal examinations. Abnormalities of saccadic eye movement and slowness of rapid alternating movements were the most common abnormalities found in at-risk individuals. Thirty persons who did not meet criteria for diagnosis at their first examination have subsequently been diagnosed with symptomatic HD. Their average age at diagnosis was $33.5 \pm$ 8.3 (SD) years. The likelihood of developing symptomatic HD within 3 years was $3 \%$ for those persons with normal first examinations, $23 \%$ for those with mildly abnormal first examinations, and $60 \%$ for those with highly abnormal first examinations. The rate of disease progression in early symptomatic cases were $1.4 \pm 0.1$ (SEM) points per year on the Shoulson-Fahn functional capacity scale. Paternal or maternal inheritance did not appear to affect the rate of progression in this group of individuals. The data suggest that there is not a discrete age of onset but rather a prolonged period of time during which symptoms unfold. Key Words: Huntington's disease-Venezuela-Disease progression-Prospective study.
\end{abstract}

The world's largest known family with Huntington's disease (HD) is descended from a woman who lived in a fishing village on Lake Maracaibo in the State of Zulia, Venezuela, approximately 200 years

A videotape segment accompanies this article.

Address correspondence and reprint requests to Dr. J. B. Penney, Jr., University of Michigan, Neuroscience Laboratory Building, 1103 East Huron Street, Ann Arbor, MI 48104-1687, U.S.A. ago. Since 1981 , study of this family by the U.S.Venezuela Cooperative Huntington's Disease Project has led to the localization of the HD gene on the tip of the short arm of chromosome 4 (1). Homozygotes for the HD gene have been identified and it appears that the HD phenotype is identical in heterozygotes and homozygotes (2). Because of the size of nuclear families within the extended pedigree, the kindred can also be used as a "reference 
pedigree," that is, to map the normal inheritance of DNA markers and genes. Normal maps of various chromosomes have been used to help localize genes for familial Alzheimer's disease, manic depression, two forms of neurofibromatosis, myotonic dystrophy, renal carcinoma, and many other genes $(3,4 ; \mathrm{J}$. Gusella, personal communication).

A large number of persons at risk and symptomatic for HD have been examined prospectively between 1981 and 1988, providing new insights into the natural history of the disease. In an initial report, we examined the natural history of symptomatic HD (5). In this report, we address the issues of age of onset and neurological signs in individuals at risk for the illness.

\section{METHODS}

Each year, from 1981 to 1988 , a priority list was generated, according to certain criteria, of individuals sought for neurological examinations (Table 1). As many family members as possible were examined. Some individuals have been examined each year consecutively, whereas others were in distant places or were unavailable for many years at a time.

Each person was tested neurologically by one or more of six neurologists. The examinations were recorded on a standardized, quantitative form using rating scales described previously $(5,6)$. Certain features of the examination were analyzed in detail (Table 2) and are shown in the accompanying videotape. Performing multiple examinations on the same individuals allowed interrater reliability to be determined $(7,8)$. Examinations were also videotaped to obtain a permanent record of the data. For those persons with unequivocal HD, the ShoulsonFahn total functional capacity (TFC) score was determined $(9,10)$.

At the end of each examination, the examiner's

\section{TABLE 1. Priorities for neurologic examinations}

Those persons with known HD

Those persons potentially homozygous for the HD gene (both parents affected)

Those persons with an abnormal prior examination

Those individuals suspected to have HD by report of other family members or friends

Persons with $\mathrm{a} \geqslant 50 \%$ risk of $\mathrm{HD}$

Persons with $a \geqslant 25 \%$ risk of HD if they are the offspring of potential homozygotes or of individuals at $50 \%$ risk with abnormal examinations

HD, Huntington's disease.
TABLE 2. Features of the neurological examination that were examined in detail

Shoulson/Fahn total functional capacity $(13=$ normal, $0=$ total care)

Chorea-at rest and under stress $(0=$ normal, $4=$ severe $)$

Dystonia-axial and limb posturing $(0=$ normal, $4=$ severe $)$

Parkinsonism-bradykinesia, rigidity, and tremor $(0=$ normal, $4=$ severe)

Saccades-latency, accuracy, speed, need for a blink or head movement for initiation $(0=$ normal, $4=$ severely abnormal)

Rapid alternating movements (RAM)-speed of finger tapping and hand pronation/supination ( $0=$ normal, $4=$ unable)

overall impression of the examinee's HD status was recorded. These impressions were scored as follows: score 0 represented someone whose neurological exam was not suggestive of HD; score 1 represented someone whose examination showed minor abnormalities minimally suggestive of $\mathrm{HD}$; score 2 represented someone whose examination showed definite abnormalities but did not unequivocally meet the criteria for diagnosis; and score 3 represented someone whose examination showed chorea, abnormal fine motor coordination, or other features that were unequivocally indicative of clinical HD. Examiners were conservative in making the diagnosis of HD. One reason for this rigor was that diagnoses determined how a person was to be coded for genetic analysis. If a genetic linkage analysis revealed a person to have the haplotype of the marker usually segregating with the normal allele of the "HD gene," the examiner had to be sufficiently confident of the clinical diagnosis to insist that it was correct and that a genetic recombination event must have taken place between the marker and gene in that individual. (Recombination is crossing over during meiosis so that the markers on one chromosome switch places with those on the homologous chromosome.)

Summary data of each subject's examination [demographic data, TFC, degree of chorea, degree of parkinsonism (tremor, rigidity and bradykinesia), degree of dystonia, degree of dysdiadochokinesia, degree of ocular motor abnormality] and the examiner's overall impression from each examination were entered into a computerized relational database. Statistical analyses ( $t$ tests, correlation coefficients, analyses of variance, and Cohen's kappas) of the data from the database were then performed.

The videotape was prepared in conjunction with the University of Michigan Biomedical Media Divi- 
sion. Informed consent was obtained from all subjects participating in this study.

\section{RESULTS}

From 1981 to $1988,1,551$ neurological examinations were performed on 593 people. People particularly important to the genetic analysis were examined multiple times by different neurologists. Of these 593 persons, 128 had definite HD, 17 had a $75 \%$ risk of carrying the HD gene, 363 had a $50 \%$ risk, 11 had a $37.5 \%$ risk, and 74 had a $25 \%$ risk. (Persons with $75 \%$ risk were offspring of two parents with HD and persons with $37.5 \%$ risk were offspring of these unaffected $75 \%$ risk individuals. Many persons have at-risk parents or one affected and one at-risk parent). Of the 74 persons with $25 \%$ risk, 5 had mildly suspicious examinations (score 1); none had a higher score. Of the 11 persons with $37.5 \%$ risk, 2 had score 1 examinations; none had a higher score. The 508 persons who were either affected or $\geqslant 50 \%$ risk for HD included 209 with normal examinations and 299 with abnormal examinations (Table 3). Of the persons with abnormal examinations, 123 were minimally suspicious for HD (score 1), 48 were highly suspicious (score 2), and 128 had definite HD (score 3). Between 1981 and $1988,15 \mathrm{HD}$ patients died. The average age at death of the 13 deceased patients whose ages were known was $45 \pm 14$ (SD) years. If the two juvenile rigid cases were excluded from the analysis, the mean age at death was $49.8 \pm 6.8$ years. In 1988,341 examinations were performed on 283 people. Of the 1988 exams, 110 were performed on 81 HD patients (these included 23 new diagnoses of HD made on at-risk persons followed prospectively and on cases new to our acquaintance). Interrater reliability scores indicated interexaminer Spearman rank correlation coefficients for all features of the examination of .61 to .92 ( $p<.05$ for all pairs of examiners).

TABLE 3. Current status of the 508 examinees: symptomatic patients and those with $\geqslant 50 \%$ risk for Huntington's disease (HD)

\begin{tabular}{ccc}
$\begin{array}{c}\text { No. of } \\
\text { patients }\end{array}$ & \multicolumn{1}{c}{$\begin{array}{c}\text { Neurological } \\
\text { diagnosis }\end{array}$} & $\begin{array}{c}\text { Neurological } \\
\text { examination } \\
\text { score }\end{array}$ \\
\hline 209 & $\begin{array}{l}\text { Normal examination } \\
\text { Abnormal examination: minimal } \\
\text { neurological impairment } \\
\text { Abnormal examination: highly } \\
\text { suspicious for HD }\end{array}$ & $\begin{array}{c}\text { Score 0 } \\
\text { Score } 1\end{array}$ \\
$128^{\circ}$ & Unequivocal HD & Score 2 \\
\hline
\end{tabular}

${ }^{a}$ Fifteen persons with HD have died since 1981.
The overall interrater agreement on the diagnostic criteria was $84 \%$ (kappa $=.61$ ), indicating substantial interrater reliability $(7,8)$. The weighted overall agreement on the TFC scores was $89 \%$ (weighted kappa $=.71$, substantial agreement).

Not surprisingly, symptomatic HD patients (Table 4) were older than those persons with merely suspicious examinations. Those persons at $\geqslant 50 \%$ risk with normal examinations showed a biphasic age distribution, with the majority being similar in age to the persons with suspicious examinations.

HD patients have been followed for an average of 3.7 years each for the 92 persons examined more than once. At-risk persons ( $\geqslant 50 \%$ risk) have been followed for an average of 2.9 years each for the 165 persons examined more than once. The rate of progression of the HD patients with adult-onset disease as determined by analysis of sequential ratings on the Shoulson-Fahn scale approximated a linear function and declined at the same rate between TFCs of 13 and 7 with a loss of $1.4 \pm 0.1$ (SEM) TFC units/year (Fig. 1). There was no significant difference in the rate of progression between those who inherited the disease from their father (27 persons) [decline $=1.4 \pm 0.3$ (SEM) TFC units/year] and those who inherited the disease from their mother (40 persons) $[1.5 \pm 0.2(\mathrm{SEM}) \mathrm{TFC}$ units/year].

Neurological abnormalities at the various stages of disease were very similar to those found in our previous analysis of 3 years of data from the same population (Fig. 2) (5). The presence of a movement disorder was a necessary criteria for the diagnosis of $\mathrm{HD}$ in an individual person. At the time of diag-

TABLE 4. Examination status of those persons who are symptomatic or who have $\geqslant 50 \%$ risk of $H D$, who have been examined, who are living, and whose ages are known

\begin{tabular}{ccccr}
\hline & \multicolumn{4}{c}{ No. of patients } \\
\cline { 2 - 5 } Age & Examined & Normal & Abnormal & HD \\
\hline$>59$ & 31 & 19 & 3 & 9 \\
$50-59$ & 50 & 17 & 6 & 27 \\
$45-49$ & 36 & 4 & 8 & 24 \\
$40-44$ & 50 & 15 & 15 & 20 \\
$35-39$ & 42 & 14 & 16 & 12 \\
$30-35$ & 54 & 19 & 22 & 13 \\
$25-29$ & 82 & 38 & 35 & 9 \\
$20-24$ & 49 & 20 & 27 & 2 \\
$15-19$ & 37 & 13 & 20 & 4 \\
$10-14$ & 7 & 2 & 4 & 1 \\
$0-9$ & 5 & 3 & 1 & 1 \\
\hline
\end{tabular}

HD, Huntington's disease. 
YEARLY DECLINE IN TOTAL FUNCTIONAL CAPACITY (TFC)

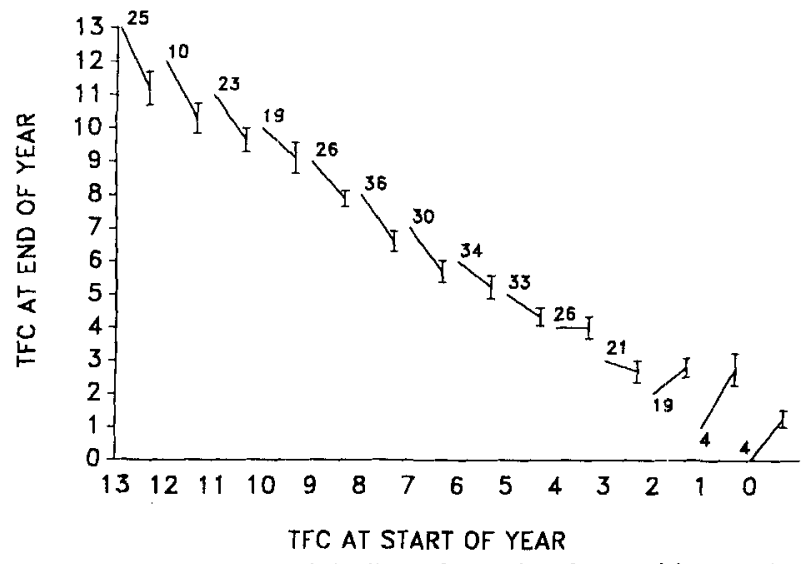

FIG. 1. Average rate of decline of functional capacities on the Shoulson-Fahn scale for the patients with adult-onset disease. The total functional capacity (TFC) values for the group of patients examined at any time point and found to have that TFC are plotted as the first point. The second point for each TFC was derived by calculating the average decline of that group's TFC in the next year and subtracting that from the initial TFC (bars = SEM). The number of persons in each group is given by the first point in each set. Data for each year of follow-up for every patient is included. The apparent increase in follow-up TFC of those with low initial TFCs is due to the fact that those who died in the next year were not included in the data set.

nosis, there were invariably abnormalities of saccadic eye movements and fine motor control. The latter abnormalities were also found in many persons at risk for HD. In cases of adult onset, chorea,

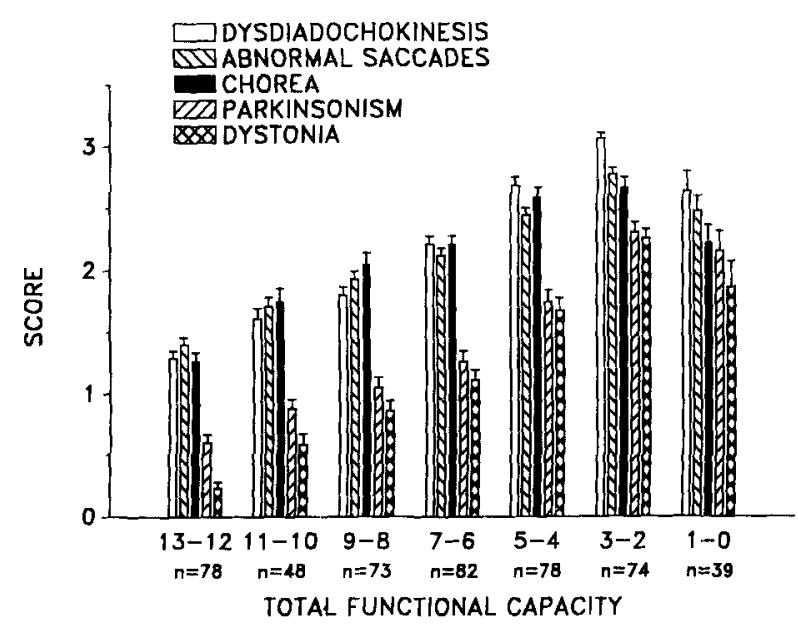

FIG. 2. Profile of motor features according to total functional capacity. Normal ability is 0 ; severely impaired is 3 . The scores for each category of disability were averaged (error bars = SEM). Juvenile cases were excluded from the analysis. The examination of each adult patient from every year they were examined is included in the analysis. The number of patients examined at each functional capacity is indicated below each set of bars. eye movement, and fine motor abnormalities developed earlier in the course of the disease than did the parkinsonian and dystonic features, which tended to be late-appearing phenomena. The chorea, eye movement, and fine motor abnormalities increased rapidly in the initial stages and then plateaued. The parkinsonian and dystonic features developed slowly in the early phases of illness and then accelerated in the later stages.

Analysis of the follow-up examinations on individuals at risk made it possible to estimate the length of time an at-risk person had an abnormal examination before diagnosis (Table 5). The $30 \mathrm{sub}$ jects who changed from being at risk to symptomatic have been included under both categories. One hundred two persons had an initially normal examination (score 0) and three of these persons have since been diagnosed with symptomatic HD after an average follow-up of 2.7 years (i.e., a $3 \%$ chance of developing symptomatic HD in 2.7 years). Of the 66 persons with mildly abnormal initial examinations (score 1), 15 persons (23\%) have developed symptomatic HD after an average of 3.1 years. Finally, 12 persons $(60 \%)$ of the 20 persons with highly suspicious initial examinations (score 2 ) developed HD after an average of 2.0 years. The patients' rate of progression of signs and chances of developing symptomatic HD within the follow-up period were not significantly affected by age or whether saccadic or fine motor abnormalities were more prominent. Overall, 30 persons who were not considered to have diagnosable HD on their first examination have since been diagnosed (Table 6). The average age at diagnosis in this group of patients was $33.5 \pm$ 8.3 (SD) years. Although those who inherited the disease from their father had a slightly younger age of onset than those who inherited the disease from their mother, the difference was not statistically significant.

\section{DISCUSSION}

The Venezuelan pedigree represents the largest Huntington's disease kindred in the world. The large number of living people at risk for the disease assures that new HD cases will develop at a rapid rate in the future. Since 1981, many persons with symptomatic $\mathrm{HD}$ and with $\geqslant 50 \%$ risk for $\mathrm{HD}$ have been followed prospectively. Of 593 persons examined, 128 (or 21\%) had symptomatic HD and 171 (or $30 \%$ ) of persons with $\geqslant 50 \%$ risk for HD had abnormal but not diagnostic examinations. Although the percentage of abnormal examinations was higher 
TABLE 5. Follow-up examinations on persons symptomatic or $\geqslant 50 \%$ at risk for Huntington's disease

\begin{tabular}{ccc}
\hline $\begin{array}{l}\text { Those persons with an initial normal examination (score 0) } \\
38\end{array}$ & Remain normal & After $3.2 \pm 1.8 \mathrm{yr}$ \\
53 & Became abnormal & After $2.9 \pm 1.5 \mathrm{yr}$ \\
8 & Became highly suspicious & After $3.5 \pm 2.0 \mathrm{yr}$ \\
3 & Were diagnosed & After $2.7 \pm 1.5 \mathrm{yr}$ \\
& Those persons & with an initial mildly abnormal examination (score 1) \\
31 & Remain abnormal & After $3.1 \pm 1.8 \mathrm{yr}$ \\
20 & Became highly suspicious & After $3.1 \pm 1.7 \mathrm{yr}$ \\
15 & Were diagnosed & After $3.1 \pm 1.5 \mathrm{yr}$ \\
Those persons & with an initial highly suspicious examination (score 2) \\
8 & Remain highly suspicious & After $2.0 \pm 1.1 \mathrm{yr}$ \\
12 & Were diagnosed & After $2.0 \pm 1.3 \mathrm{yr}$ \\
\hline
\end{tabular}

than expected for this young population, ascertainment bias likely played a role because an extra effort was made to examine those individuals in the family who were reported to have problems. Normal individuals in the older age groups were also disproportionately not ascertained, probably for the same reason. Nevertheless, the 23 new diagnoses in 1988 may not be atypical of the number of diagnoses to be made during the next few years. This family will be a continuing source of genetic and clinical information about Huntington's disease.

It has not been possible to retrospectively determine the age of onset of definitive HD in those persons who were found to be symptomatic on our first examination. The family members are the only source of information and although they are extremely sensitive to early abnormalities, their observations sometimes lack specificity. Furthermore, family members often disagree on specific dates of events. They often do not know their own ages, let alone the dates of other significant events.

The repeated examinations of at-risk persons in this study have afforded an opportunity to evaluate prospectively the timing and patterning of the initial signs of disease onset. The average onset of definitive signs sufficient for diagnosis in this population

TABLE 6. Parental effects of symptom onset in 30 patients who developed unequivocal signs of Huntington's disease $(H D)$ after their first examination

\begin{tabular}{lrcc}
\hline $\begin{array}{l}\text { Parent } \\
\text { with } \\
\text { HD }\end{array}$ & $\mathrm{N}$ & $\begin{array}{c}\text { Age at } \\
\text { diagnosis }\end{array}$ & $\begin{array}{c}\text { Known } \\
\text { years of } \\
\text { abnormality }\end{array}$ \\
\hline Father & 6 & $28.2 \pm 14.3$ & $2.5 \pm 1.2$ \\
Mother & 19 & $34.8 \pm 5.6$ & $2.5 \pm 2.0$ \\
Both & 4 & $33.0 \pm 4.7$ & $4.3 \pm 1.7$ \\
Total & 30 & $33.5 \pm 8.3$ & $2.8 \pm 1.8$ \\
\hline
\end{tabular}

was 33.5 years. This age is somewhat younger than the average age of diagnosis in U.S. populations (ages 35-40) (11). This difference most likely represents the difference in ascertainment between the Venezuelan population and the U.S. population. In the Venezuelan study, the patients were studied prospectively to determine who had signs of the disease. In prior studies from the United States, physicians had to wait until the patients presented themselves for diagnosis. Another factor may be demographic. The young age, in general, of this population of at-risk individuals will result in earlier ascertainment of those individuals with relatively young age of onset. Older ages of onset cannot yet be ascertained because the population as a whole has not achieved these ages. Continued evaluation of the family will be necessary to unequivocally address this issue. The average age of onset might rise with time if the apparently earlier age of onset is due to population demographics alone.

Whatever the age of onset may be, prospective study of disease onset demonstrates that abnormalities on neurological examination are common long before the appearance of overt signs of HD. In fact, there seems to be a "zone of onset" rather than a discrete age of onset. Very few patients who were normal on initial examination then rapidly developed HD. Most patients go through a progression of signs from mild saccadic and fine motor abnormalities to more overt abnormalities and finally to definite chorea. Further follow-up will define more clearly the periods involved in the progression through these presymptomatic stages of the disease. Our preliminary results at this point indicate that patients with a normal examination have only an approximately $3 \%$ risk of developing HD within the next 3 years whereas those with abnormal examinations have a much higher risk. It is likely that, 
just as with age of onset, we have ascertained initially those individuals at the lower end of a bellshaped curve who have a more rapid progression and shorter "zone of onset." With further study, it is likely that many gene carriers will be found to have neurological abnormalities for more than 3 years before diagnosis. The fact that half of the persons examined in their early 20s (Table 4) have abnormal examinations whereas the average age at diagnosis is 33 years old suggests that abnormalities on examination could precede diagnosis by as much as $10-15$ years.

Thinking in terms of a zone of onset rather than a discrete age of onset has certain research and clinical implications. Some people are diagnosed more rapidly within this zone, which may particularly affect position emission tomography (PET) scan or computed tomography research projects that seek early HD patients as subjects. Neuropathological and neurochemical changes are occurring that produce these early signs and they are taking place at a younger age than typically thought of as the average age of symptom onset. Research examining parental sex effects on age of onset must also take this zone into account. Additionally, it would be imperative to begin a therapeutic agent-if one were to be developed-as early as possible, at the beginning of the zone rather than at the end. Finally, it can be a relief for those who test positive on presymptomatic genetic testing but who have normal examinations to know that the disease will take a long time to unfurl, even after abnormalities begin.

Long-term prospective studies of persons at risk for HD have not been possible in the past because of the lack of a large accessible cohort of subjects. This study to date has probably defined only the early portion of a "zone of onset" in HD. There appears to be a substantial period during which the brain is presumably undergoing neurochemical and neuropathological changes but during which sufficient compensation can be made so that a definitive neurological diagnosis is not possible. In the future, it will be necessary to develop more refined quantitative markers of this neurological dysfunction. Quantitative studies of eye movements such as those used in smaller groups of at-risk persons may be helpful (12). In addition, more quantitative assessments of the rate, rhythm, and speed of alternating movements could be developed. Alternatively, more sensitive markers of neuronal dysfunction might be developed for brain imaging with
PET. It is unlikely that these changes will show up with PET scans of deoxyglucose metabolism (13). The development of more accurate markers of early neurological and neuronal dysfunction in HD will be important for research and clinical therapeutics.

In this study, the neurological abnormalities in symptomatic persons varied with the stage of the disease. Even in the at-risk population, abnormalities appeared in a predictable sequence. Abnormalities in fine motor movements and rapid saccades developed early. At-risk individuals with these abnormalities were more likely than those without them to develop overt HD within several years, suggesting that these findings are presymptomatic signs of the disease. When a movement disorder appeared, a definite diagnosis was possible. This initial movement disorder was usually chorea. The chorea, fine motor abnormalities, and saccadic abnormalities tended to progress together in the early stages of the disease. Parkinsonism and dystonia developed later in typical adult-onset cases and became more severe in the later portions of the disease when chorea may have actually declined. The decline in chorea in the Venezuelan population was not as great as that seen in the U.S. population (14), perhaps because the persons with $\mathrm{HD}$ die at a younger age in Venezuela and at an earlier stage of the disease. In addition, the Venezuelan patients rarely received neuroleptic therapy, which may influence symptom expression. [The average age at death in the United States is 58.7 years based on a bigger number of patients (15), compared with the 8 years younger age in Venezuela. The earlier age of death in Venezuela is probably due to the lack of skilled nursing care for these patients.]

The change in the character of neurological signs with disease progression may have significance in light of recent findings about the pathological anatomy of the disease (16). Striatal projections to the substantia nigra pars reticulata and the lateral globus pallidus appear to be affected early in HD, before the striatal pathway to the medial globus pallidus is affected. Work in experimental animals has shown that the pathway from striatum through substantia nigra pars reticulata to superior colliculus is important to the generation of saccades. Abnormalities of striatal output to substantia nigra pars reticulata would be expected to result in abnormal saccades. It is tempting to speculate that the fine motor abnormalities and the chorea arise from disease of the striatal projection to lateral globus pallidus (17). 
The lateral globus pallidus has a major inhibitory effect on the subthalamic nucleus. Loss of striatal projections to lateral globus pallidus would disinhibit the lateral globus pallidus, which would in turn overinhibit the subthalamic nucleus. (Lesions of the subthalamic nucleus cause choreiform movements in primates and humans.) The later appearance of parkinsonism and dystonia in HD may reflect subsequent disease of the striatal projection to medial globus pallidus.

The rate of decline of the TFC in the HD patients was linear and rapid in stage I (TFC 13-11) and stage II (TFC 10-7) of the disease. The decline became less rapid and more variable at later stages of the disease. This change probably represents a weighting of the Shoulson-Fahn scale toward measurements of early decline, particularly cognitive disabilities. PET studies have suggested a linear decline in caudate glucose metabolism in the same early-stage patients (18). The slower decline in later-stage patients may reflect both insensitivity of the scale and the fact that neuronal loss may be slower in the later stages of the illness. Scales that are more sensitive to changes in the later stages of the illness, such as that of Myers et al. (19), have not been used with the Venezuela population.

Recent studies have suggested that the rate of decline in HD patients reflects the age of onset and the parental source of inheritance (10). We did not find a difference in the rate of decline between those with paternal and those with maternal inheritance. Several factors could explain this apparent lack of parental effect. First, it may be necessary to analyze larger numbers of patients to see such an effect. Second, many unaffected parents are descended from patients and may share modifying genes that influence disease progression and mask the role of parental effects. Third, parental factors may play less of a role in the rate of decline than suspected from the recent studies.

Acknowledgment: Supported by the Hereditary Disease Foundation, United States Public Health Service grant NS22031, the W. M. Keck Foundation, and the Vollmer Foundation. We are grateful to R. Stephen Uzzell for film footage of some of the patients. We give our special thanks to all the persons in the Venezuelan family who donated their time and cooperation to this project.

\section{LEGEND TO THE VIDEOTAPE}

Selected portions of the neurological examinations of some members of the Venezuelan family are shown.

\section{REFERENCES}

1. Gusella JF, Wexler NS, Conneally PM, et al. A polymorphic DNA marker genetically linked to Huntington's disease. $\mathrm{Na}$ ture 1983;306:234-238.

2. Wexler NS, Young AB, Tanzi RE, et al. Homozygotes for Huntington's disease. Nature 1987;326:194-197.

3. St George-Hyslop PH, Tanzi RE, Polinsky RJ, et al. The genetic defect causing familial Alzheimer's disease maps on chromosome 21. Science 1987;235:885-890.

4. Egeland JA, Gerhard DS, Pauls DL, et al. Bipolar affective disorders linked to DNA markers on chromosome 11. $\mathrm{Na}$ ture 1987;325:783-788.

5. Young AB, Shoulson I, Penney JB, et al. Huntington's disease in Venezuela: neurologic features and functional decline. Neurology 1986;36:244-249.

6. Folstein SE, Jensen B, Leigh RJ, Folstein MF. The measurement of abnormal movement: methods developed for Huntingtons disease. Neurobehav Toxicol Teratol 1983; 5:605-609.

7. Kramer MS, Feinstein AR. Clinical biostatistics: LIV. The biostatistics of concordance. Clin Pharmacol Ther 1981; 29:111-123.

8. Flies JL. Statistical methods for rates and proportions. New York: John Wiley, 1981:212-236.

9. Shoulson I, Fahn S. Huntington's disease: clinical care and evaluation. Neurology 1979;29:1-3.

10. Shoulson I, Odoroff C, Oakes D, et al. A controlled clinical trial of baclofen as protective therapy in early Huntington's disease. Ann Neurol 1989;25:252-259.

11. Farrer LA, Conneally MP. A genetic model for age at onset in Huntington disease. Am J Hum Genet 1985;37:350-357.

12. Lasker AG, Zee DS, Hain TC, Folstein SE, Singer HS. Saccades in Huntington's disease: slowing and dysmetria. Neurology 1988;38:427-431.

13. Young AB, Penney JB, Starosta-Rubenstein S, et al. Normal glucose metabolism in persons at risk for Huntington's disease. Arch. Neurol. 1987;44:254-257.

14. Shoulson I. Huntington's disease. In: Asbury AK, McKhann GM, McDonald WI, eds. Diseases of the nervous system. Clinical neurobiology. Philadelphia: WB Saunders, 1986:1258-1267.

15. Lanska DJ, Lavine L, Lanska MJ, Schoenberg BS. Huntington's disease mortality in the United States. Neurology 1988;38:769-772.

16. Reiner A, Albin RL, Anderson KD, D'Amato CJ, Penney $\mathrm{JB}$, Young AB. Differential loss of striatal projection neurons in Huntington disease. Proc Natl Acad Sci USA 1988;85:5733-5737.

17. Penney JB, Young AB. Striatal inhomogeneities and basal ganglia function. Movement Disorders 1986;1:3-15.

18. Young AB, Penney JB, Starosta-Rubenstein S, et al. PET scan investigations of Huntington's disease: cerebral metabolic correlates of neurological features and functional decline. Ann Neurol 1986;20:296-303.

19. Myers RH, Sax DS, Schoenfeld M, Bird ED, Wolf PA, Vonsattel JP, White RF, Martin JB. Late onset of Huntington's disease. J Neurol Neurosurg Psychiatry 1985;48:530-534. 